\title{
Transient attention does increase perceived contrast of suprathreshold stimuli: A reply to Prinzmetal, Long, and Leonhardt (2008)
}

\author{
Marisa Carrasco and Stuart Fuller \\ New York University, New York, New York \\ AND \\ SAM LING \\ Vanderbilt University, Nashville, Tennessee
}

\begin{abstract}
Carrasco, Ling, and Read (2004) showed that transient attention increases perceived contrast. However, Prinzmetal, Long, and Leonhardt (2008) suggest that for targets of low visibility, observers may bias their response toward the cued location, and they propose a cue-bias explanation for our previous results. Our response is threefold. First, we outline several key methodological differences between the studies that could account for the different results. We conclude that the cue-bias hypothesis is a plausible explanation for Prinzmetal et al.'s (2008) results, given the characteristics of their stimuli, but not for the studies by Carrasco and colleagues, in which the stimuli were suprathreshold (Carrasco, Ling, \& Read, 2004; Fuller, Rodriguez, \& Carrasco, 2008; Ling \& Carrasco, 2007). Second, we conduct a study to show that the stimuli used in our previous studies are not near-threshold, but suprathreshold (Experiment 1, Phase 1). Furthermore, we found an increase in apparent contrast for a highcontrast stimulus when it was precued, but not when it was postcued, providing more evidence against a cue-bias hypothesis (Experiment 1, Phase 2). We also show that the visibility of the stimuli in Prinzmetal et al. (2008) was much lower than that of Carrasco, Ling, and Read, rendering their stimuli susceptible to their cue-bias explanation (Experiment 2). Third, we present a comprehensive summary of all the control conditions used in different labs that have ruled out a cue bias explanation of the appearance studies. We conclude that a cue-bias explanation may operate with near-threshold and low-visibility stimuli, as was the case in Prinzmetal et al. (2008), but that such an explanation has no bearing on studies with suprathreshold stimuli. Consistent with our previous studies, the present data support the claim that attention does alter the contrast appearance of suprathreshold stimuli.
\end{abstract}

\section{Attention and Appearance}

Psychologists, physiologists, and philosophers alike have debated the phenomenology of attention for over a century: Does attention alter our subjective experience of the visual world? Which aspects of our visual experience does attention affect? Can attention make a visual pattern seem more detailed, or a color more vivid? Surprisingly, only very recently have the questions of whether and how attention affects appearance been systematically investigated. This may be due to the difficulty of objectively testing and quantifying the subjective experience of perceived stimuli and changes in such experience with attention. The phenomenology of selective attention has been a subject of debate among pioneers in experimental psychology, such as Mach, Fechner, von Helmholtz, Wundt, and James (see James, 1890/1950; Wundt, 1902). Much of this early work was introspective, and conflicting conclusions were often drawn from such subjective methods of investigation. On the disagreement among investigators about whether attention increases the perceived intensity of a stimulus, James concluded, "The subject is one which would well repay exact experiment, if methods could be devised" (p. 426).

Carrasco, Ling, and Read (2004) developed a psychophysical paradigm that assesses the phenomenological correlate of attention, by manipulating transient attention via uninformative spatial cues, making it possible to study subjective experience and visual awareness more objectively and rigorously (Luck, 2004; Treue, 2004). This paradigm quantifies the observer's subjective perception using a task contingent upon a comparative judgment between two stimuli on a particular feature (Carrasco, Ling, \& Read, 2004). Observers are shown two stimuli and asked to "report property $x$ (e.g., orientation) of the stimulus that is greater/lesser in property $y$ (e.g., contrast)." That is, the perceived relative value of property $y$ - the primary interest of the experiment-is an indicator of which stimulus to report on property $x$. The critical manipulation is that observers are not asked to directly rate their subjective experience on property $y$, but to make a decision about

M. Carrasco, marisa.carrasco@nyu.edu 
stimulus property $x$. This experimental design, which allows simultaneous measurement of the effects of attention on both performance and appearance, emphasized to the observers the orientation judgment, when in fact we were interested in their contrast judgments. This instruction makes it less likely that observers' responses are driven by biases and expectations. This paradigm, coupled with control experiments, has ruled out alternative cue bias and response bias explanations (see Discussion).

Using this appearance paradigm, studies on the phenomenological correlates of attention have shown that attention alters appearance of basic spatial — contrast, spatial resolution, color saturation, object size - and temporalflicker rate, motion coherence, speed - visual dimensions (for a review, see Carrasco, in press). We will use this paradigm in the experiment reported in this reply.

\section{Transient Attention Alters Contrast Appearance (Carrasco, Ling, \& Read, 2004)}

Contrast, a fundamental dimension of vision, is a natural candidate for understanding the relation between attention and appearance. Psychophysical (e.g., Carrasco, Talgar, \& Eckstein, 2000; Dosher \& Lu, 2000a, 2000b; Huang \& Dobkins, 2005; Ling \& Carrasco, 2006a, 2006b; Lu \& Dosher, 1998; Morrone, Denti, \& Spinelli, 2004; Pestilli \& Carrasco, 2005), electrophysiological (e.g., Lee, Williford, \& Maunsell, 2007; Martinez-Trujillo \& Treue, 2002; Reynolds, Pasternak, \& Desimone, 2000; Williford \& Maunsell, 2006), and neuroimaging (e.g., Buracas \& Boynton, 2007; Liu, Pestilli, \& Carrasco, 2005; Murray \& $\mathrm{He}, 2006)$ studies indicate that attention increases contrast sensitivity (for reviews, see Carrasco, 2006; Reynolds \& Chelazzi, 2004).

In the Carrasco, Ling, and Read (2004) study, to investigate the effects of transient attention on perceived contrast, observers were presented with two Gabor patches, one to the left and one to the right of fixation, and were asked to report the orientation (left or right tilt) of the higher contrast stimulus (see Figure 1). These instructions emphasized the orientation judgment, when in fact the main interest was their contrast judgments. On each trial, the standard Gabor was of a fixed contrast, whereas the contrast of the test Gabor was randomly chosen from a range of contrasts sampled around the standard contrast. The orientation of each Gabor was chosen randomly. By assessing observers' responses, we obtained the psychometric functions describing the probability of choosing the test relative to the standard, as a function of their contrast. The test contrast at which this function reaches $50 \%$ is the point of subjective equality (PSE). These functions were measured when transient covert attention was automatically directed to the cued location, via a peripheral cue, and when it was distributed across the display, via a neutral cue. The peripheral cue was uninformative in terms of both stimulus orientation and contrast. Observers were told that the peripheral cue had equal probability of appearing either to the left or right of fixation and above the higher or lower contrast stimulus. This eliminated the possibility of observers giving more weight to the information at the cued location and hence a decisional explanation for an attentional effect.

Transient attention significantly increased perceived contrast. In the neutral condition, the PSE occurred at physical equality. When the test patch was cued, the PSE shifted to lower test contrasts, indicating that less contrast is needed for the test to match the standard; conversely, when the standard patch was cued, the PSE shifted to higher test contrasts, indicating that more contrast is needed for the test to match the standard. The effects were similar for low- and high-contrast stimuli. Because observers performed an orientation discrimination task contingent upon appearance, an objective index showed that the cue improved performance in the discrimination task. The results further argued against response bias, which should not produce a change in discrimination performance. In sum, when observers'

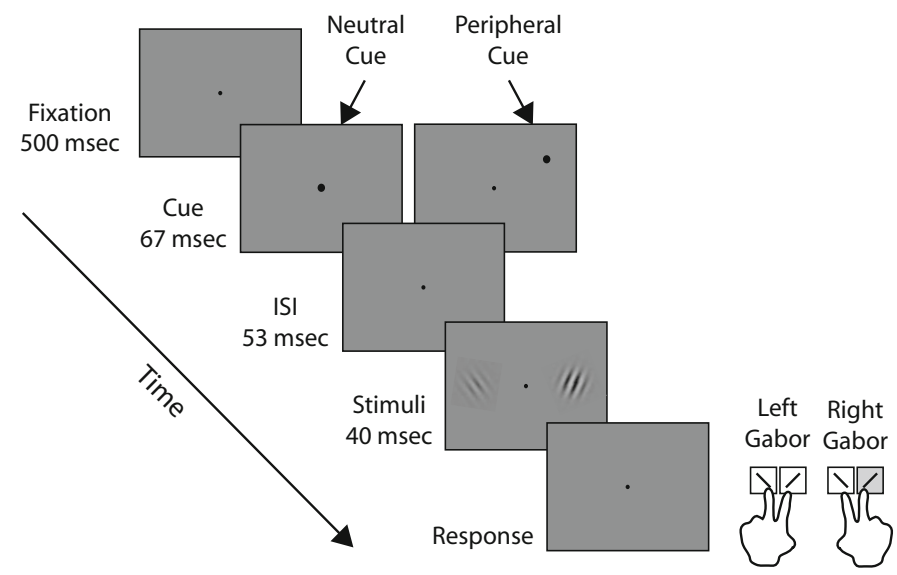

Figure 1. Trial sequence as used by Carrasco, Ling, and Read (2004). The observers' task is to report the position (relative to fixation) and orientation of the higher (or lower, depending on instructions) Gabor stimulus in a simultaneously presented pair. The peripheral cue is completely uninformative about the relative contrasts, positions, and orientations of the stimuli. 
attention was drawn to a stimulus location, observers reported stimulus as being higher in contrast than it actually was, thus indicating that attention changes appearance.

These results have been replicated by Schneider (personal communication, 2008; Schneider \& Komlos, 2008), as well as under conditions in which the cue contrast polarity changed (Ling \& Carrasco, 2007) and when the stimuli appeared along the vertical meridian (Fuller, Rodriguez, \& Carrasco, 2008). Moreover, an attentional effect consistent with our findings has been obtained using low-contrast sine wave gratings (Hsieh, Caplovitz, \& Tse, 2005).

With this paradigm, the attentional effect is greater in the dynamic range of the psychometric function, with test stimulus contrasts at and surrounding the standard stimulus contrast. Because the task involves a relative judgment between the two stimuli, the absolute contrast value of the test stimulus is irrelevant. The following examples illustrate this point. First, Carrasco, Ling, and Read (2004) used a test contrast range of $2.5 \%$ to $16 \%$ with a standard of $6 \%$ in Experiment 1, and 6\% to $79 \%$ with a standard of $22 \%$ in Experiment 2. Whereas in the former there was no attention effect with $16 \%$ test stimulus contrast, because the function had reached asymptote (observers always chose the test over the standard as being higher in contrast), in the latter there was an attention effect, because this test contrast value was in the dynamic range. Furthermore, $16 \%$ contrast was the only common test contrast in two experiments in Fuller et al. (2008). There was no attention effect in either case, because it was the highest value among the test contrasts in Experiment 2 and the lowest in Experiment 3, for which observers always, or never, respectively, selected the test stimulus.

\section{Prinzmetal, Long, and Leonhardt (2008)}

Prinzmetal, Long, and Leonhardt (2008) suggest an alternative explanation for the finding of Carrasco, Ling, and Read (2004) that transient attention increases perceived contrast. The authors hypothesize that these findings are not due to a change in perceived contrast, but rather to a bias that occurs when observers have difficulty detecting the stimuli at low, near-threshold contrasts. Prinzmetal et al. (2008) argue that when a salient exogenous cue appears, observers are biased to report that the higher contrast stimulus appeared at the cued location. This conclusion is based on five experiments, in which the authors report (1) a cuing effect with near-threshold stimuli; (2) no effect with higher contrast stimuli; (3) a bias toward the cue in a detection task; (4) a postcue yielding similar results to a precue; and (5) a tendency to report the cue location in the absence of stimuli.

We (Carrasco, Ling, \& Read, 2004; Fuller \& Carrasco, 2006; Fuller et al., 2008; Gobell \& Carrasco, 2005; Ling \& Carrasco, 2007; Liu, Fuller, \& Carrasco, 2006; Montagna $\&$ Carrasco, 2006) and others (Anton-Erxleben, Henrich, \& Treue, 2007; Hsieh et al., 2005; Turatto, Vescovi, \& Valsecchi, 2007) have conducted numerous control experiments to ensure that our results do not simply arise from a cue bias; we will highlight them all in detail in the Discussion. Here we argue that the cue bias hypothesis laid forth by Prinzmetal et al. (2008) is a plausible account of their particular results, because of the characteristics of their stimuli: When the stimuli are absent, are near threshold, or are of low visibility, responses may be biased toward the cued side. However, the visibility of the stimuli used in their experiments - determined not only by contrast, but also by spatial frequency, stimulus size, and interstimulus distance - differed quantitatively and qualitatively from the visibility of the stimuli used in Carrasco, Ling, and Read (2004), and these differences make any rigorous comparisons between the experiments impossible.

\section{Key Methodological Differences Between Prinzmetal et al. (2008) and Carrasco, Ling, and Read (2004)}

Although Prinzmetal et al. (2008) purport to replicate the results of Carrasco, Ling, and Read (2004) by using similar conditions, there are a number of key methodological differences that prevent rigorous comparisons between the two studies. To replicate is "to make or do something again in exactly the same way" (Cambridge Dictionary). In science,

the methods employed by a researcher are repeated in an effort to confirm or disconfirm the findings obtained. ... An important distinction: replication refers to repeating the experiment, not to confirming the original findings. . . . Unfortunately, there is a tendency for some to say that they "failed to replicate an experiment," which literally means that they failed to repeat the original methodology. (McGuigan, 1997, p. 159)

Here, we detail these differences and show that conclusions based on their results cannot be generalized to those of Carrasco, Ling, and Read (2004).

Contrast psychometric functions. Prinzmetal et al. (2008) report no effect of attention on appearance with their high-contrast stimuli (Experiment 2). They correctly point out that they specifically wanted to tap into the region of the psychometric function where there was the most potential to find an effect. However, they capture almost no data in the critical dynamic range of their psychometric functions (Prinzmetal et al., 2008; see Figure 5). The use of only four contrast levels undermines the reliability of the psychometric functions, since there are too few levels to encompass a minimum asymptote, a dynamic range, and a maximum asymptote. Moreover, in Prinzmetal et al.'s (2008) Experiments 4 and 5, the psychometric functions are rather flat, and it is not clear which data points would differ from chance-level performance (.5).

Discrimination versus detection tasks. Prinzmetal et al. (2008) show that in a detection task, there is a shift in criterion between the cued and uncued conditions; observers produce more false alarms when the stimulus is cued (their Experiment 3). This is likely the result of the low stimulus visibility (see below). The authors fail to articulate how this result speaks to the $2 \mathrm{AFC}$ discrimination experiments with suprathreshold stimuli used by Carrasco, Ling, and Read (2004).

Stimulus characteristics and visibility. Prinzmetal et al. (2008) claim to replicate Carrasco, Ling, and Read (2004) by using "very similar" conditions. However, sev- 
eral fundamental stimulus parameters known to affect both detection and discrimination are critically different in these two studies. Without empirically evaluating the visibility consequences of the different stimulus parameters, Prinzmetal et al. (2008) dismiss these differences as inconsequential. Here, we evaluate the consequences of these differences empirically, and show that they have a profound impact on the visibility of the stimuli.

Prinzmetal et al. (2008) created their stimuli by taking screen captures of the display used in Carrasco, Ling, and Read (2004), without taking into account that these stimuli were calibrated for a particular linearized monitor in the Carrasco lab. Because the monitor used in Prinzmetal et al. (2008) was not linearized, asymmetries in the presentation of the sinusoids (amplitude of the trough greater than of the peak) would lead to the net luminance covarying with their contrast manipulation, a serious confound. ${ }^{1}$ Below, we list additional critical differences, and describe how, taken together, many of them would render the stimuli in Prinzmetal et al. (2008) as near threshold, whereas the stimuli used in Carrasco, Ling, and Read (2004) were suprathreshold. The following are critical stimulus parameters:

1. Stimulus size: Carrasco, Ling, and Read (2004), $2^{\circ}$; Prinzmetal et al. (2008), $1.05^{\circ}$ (stimulus size is relevant to contrast in Barlow units; see below).

2. Spatial frequency: Carrasco, Ling, and Read (2004), 2 cpd and 4 cpd; Prinzmetal et al. (2008), $11 \mathrm{cpd}$ (Figure 2, accepted manuscript) or $7 \mathrm{cpd}$ (Figure 2, published paper).

3. Eccentricity from fixation point: Carrasco, Ling, and Read (2004), 4'; Prinzmetal et al. (2008), $1.85^{\circ}$.

4. Center to center distance between stimuli: Carrasco, Ling, and Read (2004), $8^{\circ}$; Prinzmetal et al. (2008), $3.7^{\circ}$.

5. Stimulus contrast: For comparison, we report the Carrasco, Ling, and Read (2004) contrast in Barlow units (Table 1). Because Prinzmetal et al. (2008) used stimuli that had smaller diameters than those of Carrasco, Ling, and Read (2004), in Experiment 2, Prinzmetal et al. (2008) had to increase contrast significantly to achieve comparable Barlow values to those of Carrasco, Ling, and Read (2004, Experiment 2; same contrast values for the stimuli of the experiment reported in the present article and in Ling \& Carrasco, 2007).

Among these differences, the spatial frequency and size of the stimuli are of particular interest, since the high spatial frequency, along with the smaller stimulus diameter, would render the stimuli used in Prinzmetal et al. (2008) considerably more difficult to perceive compared with the stimuli in Carrasco, Ling, and Read. Indeed, Prinzmetal et al. (2008) note that their observers had difficulty seeing the stimuli in Experiment 1 of their study, and that in fact some observers complained that they could not detect anything in some trials. Without taking into consideration the critical aforementioned differences, Prinzmetal et al. (2008) extrapolate from the lack of visibility of their own stimuli and assume that in the Carrasco, Ling, and Read study observers experienced the same difficulty in detect-
Table 1

Comparison of Stimulus Michelson Contrast and Barlow Units for Prinzmetal et al. (2008) and

Carrasco, Ling, and Read (2004, Experiment 2)

\begin{tabular}{|c|c|c|c|}
\hline & $\begin{array}{c}\text { Prinzmetal } \\
\text { et al. }(2008) \\
\text { Peak } \\
\text { Contrast }\end{array}$ & $\begin{array}{c}\text { Prinzmetal } \\
\text { et al. }(2008) \\
\text { Barlow Units } \\
10 * \log _{10}\left(\mathrm{CE} * 10^{6}\right) \\
1.05^{\circ} \text { stimuli }\end{array}$ & $\begin{array}{c}\text { Carrasco } \\
\text { et al. }(2004) \\
\text { Experiment } 2 \\
\text { Barlow Units } \\
10 * \log _{10}\left(\mathrm{CE} * 10^{6}\right) \\
2^{\circ} \text { stimuli } \\
\end{array}$ \\
\hline \multicolumn{4}{|c|}{ Experiment 1 (Prinzmetal et al., 2008) } \\
\hline Test 1 & .17 & 17.69 & 23.52 \\
\hline Test 2 & .19 & 19.16 & 24.48 \\
\hline Standard & .23 & 20.54 & 26.14 \\
\hline Test 3 & .29 & 22.72 & 28.16 \\
\hline Test 4 & .37 & 25.04 & 30.27 \\
\hline \multicolumn{4}{|c|}{ Experiment 2 (Prinzmetal et al., 2008) } \\
\hline Test 1 & .41 & 25.71 & \\
\hline Test 2 & .48 & 27.22 & \\
\hline Standard & .57 & 28.89 & \\
\hline Test 3 & .75 & 31.34 & \\
\hline Test 4 & .98 & 34.26 & \\
\hline
\end{tabular}

Note-Observe the Barlow similarity between Prinzmetal et al.'s Experiment 2 stimuli, ranging from $41 \%$ to $98 \%$ Michelson contrast, and Carrasco et al.'s larger stimuli, ranging from $17 \%$ to $37 \%$ Michelson contrast. These are only the Michelson contrast stimuli comparable to those reported by Prinzmetal et al.

ing the stimuli, inappropriately concluding that our stimuli were near threshold. Although their particular stimuli were apparently near threshold, ours were not. In sum, the stimuli in Prinzmetal et al. (2008) were smaller, at less than half the eccentricity and interstimulus distance, ${ }^{2}$ and at much higher spatial frequency (for $11 \mathrm{cpd}, 5.5 \times$ and $2.75 \times$ the spatial frequency of the 2-cpd and 4-cpd stimuli; for $7 \mathrm{cpd}, 3.5 \times$ and $1.75 \times$ the spatial frequency of the 2-cpd and 4-cpd stimuli) than the stimuli in Carrasco, Ling, and Read. The idea that the stimuli in the two studies are equivalent in visibility is unsustainable. The cue bias explanation laid forth in Prinzmetal et al. (2008) relies on their assumption that the stimuli used by Carrasco, Ling, and Read are near detection threshold.

If a response bias to the cued side could account for previous results, this would alter the interpretation of what is by now a considerable body of work (Anton-Erxleben et al., 2007; Fuller \& Carrasco, 2006; Fuller et al., 2008; Gobell \& Carrasco, 2005; Hsieh et al., 2005; Ling \& Carrasco, 2007; Liu et al., 2006; Montagna \& Carrasco, 2006; Turatto et al., 2007). Although we had piloted our stimuli to make sure they were suprathreshold, here we set out to test systematically for all observers the critical assumption that our stimuli were near threshold.

\section{EXPERIMENT 1}

The experiment was conducted in two phases. In Phase 1, 10 observers performed a localization task on the stimuli that would be used in Phase 2. In Phase 1, we empirically test the visibility of the stimuli used by Carrasco, Ling, and Read (2004, Experiment 2): Were the stimuli in our original study indeed near threshold (as claimed by Prinzmetal et al., 2008), localization performance should 
be fairly poor. Alternatively, high localization performance would indicate that the stimuli were suprathreshold, thereby excluding the findings in Carrasco, Ling, and Read from the bias explanation proposed by Prinzmetal et al. (2008). In addition, we show that the stimulus configurations used in Prinzmetal et al. (2008) are indeed very difficult to discern.

In Phase 2, to test the idea that the shift in perceived contrast with attention is due to a cue bias, for the same 10 observers we compared the effects of the precue and postcue conditions on perceived contrast using these demonstrated suprathreshold stimuli (Phase 1). This manipulation can be used to distinguish between attentional and decisional effects (Gobell \& Carrasco, 2005). Given that the spatial and temporal contiguity between cue and stimulus are the same, were the effect of appearance due to a cue bias, the pattern of results would be the same, whether the cue was presented before or after the stimuli. Alternatively, the presence of an effect with the precue and its absence with the postcue would support the interpretation that our results are due not to a bias but rather to attention affecting the apparent stimulus contrast. The results were unequivocal: We show that the perceived contrast is shifted only under the precued condition, and that there is no influence of the postcue on the psychometric functions, thus further ruling out a cue bias explanation for the contrast appearance results of Carrasco, Ling, and Read.

\section{Method}

We used the same apparatus, stimuli, and procedure as those used in studies of appearance of perceived contrast (Carrasco, Ling, and Read, 2004; Fuller et al., 2008; Ling \& Carrasco, 2007).

Observers. Ten New York University (NYU) graduate and undergraduate students participated as observers in a localization task (Phase 1) and in both the precue and postcue conditions (Phase 2). All had normal or corrected-to-normal vision.

Apparatus. The stimuli were created on a G4 Power Macintosh using MATLAB and the Psychophysics Toolbox (Brainard, 1997; Pelli, 1997). Observers viewed the stimuli on a gamma-corrected monitor (Pelli \& Zhang, 1991). A video attenuator was used to drive just the green gun of a 21 -in. monitor $(1,024 \times 768 ; 120 \mathrm{~Hz})$, thus providing a larger possible set of distinct luminance levels ( 12.6 bits). Background luminance was set to $9.86 \mathrm{~cd} / \mathrm{m}^{2}$. White corresponded to $39.79 \mathrm{~cd} / \mathrm{m}^{2}$, and black to $0.01 \mathrm{~cd} / \mathrm{m}^{2}$.

Stimuli and Design. A black square $\left(0.1^{\circ} \times 0.1^{\circ}\right)$ was presented in the center of the screen of a uniform background throughout the experiment, serving as a fixation point. There were two types of cues: The peripheral cue (Phase 2$)$ was a small dot $\left(0.3^{\circ} \times 0.3^{\circ}\right)$, which appeared $1.5^{\circ}$ above the center of the location where one of the two stimuli was about to appear; the neutral cue was a small dot $\left(0.3^{\circ} \times 0.3^{\circ}\right)$ presented at fixation. Black neutral cues were used in Phase 1; black and white cues were used and randomly interleaved during Phase 2.

The stimuli were 4 -cpd Gabor patches $\left(2^{\circ}\right.$ sinusoidal gratings enveloped by a Gaussian, independently tilted $10^{\circ}$ either to the left or to the right) at Michelson contrasts from $6.3 \%$ to $69 \%$, in nine equally spaced log-contrast increments. In both phases, stimulus locations were to the left and right of fixation at $4^{\circ}$ eccentricity along the horizontal meridian ( $8^{\circ}$ center-to-center between the stimuli). In Phase 1, we presented a single stimulus per trial to assess localization. In Phase 2, we examined relative apparent contrast by presenting stimuli at both locations simultaneously. One of the Gabor patches was always presented at a fixed contrast of $21 \%$ (standard stimulus), whereas the contrast of the other Gabor (test stimulus) was randomly sampled from the full set of nine (including the stan- dard contrast). From trial to trial, the stimuli randomly varied (with equal probability) in orientation and contrast.

Procedure. Phase 1 was designed to measure observers' ability to localize our contrast Gabor stimuli. Observers viewed the display binocularly at a distance of $114 \mathrm{~cm}$ from the monitor with their heads stabilized by chinrests. They were asked to fixate on the fixation point throughout the experiment. Here we used a single stimulus per trial, randomly presented to the right or left of fixation and with random orientation $\pm 10^{\circ}$ from vertical. Each trial began with a black neutral cue presented at fixation- $67 \mathrm{msec}$, followed by a $53-\mathrm{msec}$ interstimulus interval (ISI) - to reduce temporal uncertainty of the stimulus presentation. The stimulus was presented for $40 \mathrm{msec}$, and observers were asked to report which side the stimulus appeared on. Observers were given 20 practice trials, then performed 1,000 trials in 10 blocks of 100 trials each.

In Phase 2, each observer participated in the precue and postcue conditions, each consisting of a practice block of 75 trials and five experimental blocks of 200 trials each, which lasted approximately $1 \mathrm{~h}$. In Phase 2, 9 of the 10 observers were NYU undergraduate and graduate students who had participated in Phase 1. The order of the precue and postcue conditions was counterbalanced across observers. The viewing conditions were as in Phase 1. In each trial of the precue condition, observers were presented with a fixation point for $500 \mathrm{msec}$, after which either a white or a black peripheral or neutral cue was briefly flashed $(67 \mathrm{msec})$. Following an ISI of $53 \mathrm{msec}$, the two Gabor stimuli were presented for $40 \mathrm{msec}$ (Figure 2A). In the postcue condition, the presentation order of the cue and stimulus was reversed (Figure 2B).

Observers performed a $2 \times 2$ alternative forced choice (AFC) task - they indicated the orientation of the Gabor that appeared higher in contrast. They were instructed to respond to the question "Is the higher-contrast stimulus tilted to the left or the right?" If the stimulus to the left of fixation appeared higher in contrast, observers indicated its orientation by pressing either " $Z$ " (leftward tilt) or " $X$ " (rightward tilt) with the middle or index finger of the left hand. If the stimulus to the right of fixation appeared higher in contrast, observers indicated its orientation by pressing either "." (leftward tilt) or "/" (rightward tilt) with the middle or index finger of the right hand. The peripheral cue was completely uninformative in terms of the two stimulus contrasts, location of the higher contrast stimulus, or their orientations. Observers knew that the peripheral cue was uninformative, since they were explicitly told that the cue had equal probability of appearing adjacent to either the higher or lower contrast stimulus.

The 120-msec interval between the cue onset and stimulus onset was chosen to maximize the effect of the peripheral cue in automatically eliciting transient attention (e.g., Carrasco, Ling, \& Read, 2004; Cheal \& Lyon, 1991; Nakayama \& Mackeben, 1989). The 160 -msec interval between cue onset and stimulus offset (precue condition) or between stimulus onset and cue offset (postcue condition) was chosen to preclude eye movements (Mayfrank, Kimmig, \& Fischer, 1987), thus ensuring that the observers performed the task under covert attention.

\section{Results}

Phase 1. With near-threshold or below-threshold stimuli, localization performance should be near chance. However, the stimuli were easy to localize with the stimulus configuration used in Carrasco, Ling, and Read (2004). Observers correctly localized with $90 \%$ accuracy even the lowest contrast stimulus used by Carrasco, Ling, and Read, as well as that used by Ling and Carrasco (2007), and achieved perfect localization for the other eight stimulus contrasts. Figure 3 shows the results collapsed across all observers. Localization performance indicates that the stimuli are suprathreshold and that there is no location uncertainty whatsoever for eight of the nine stimuli used (and minimal location uncertainty for the lowest stimulus contrast). 


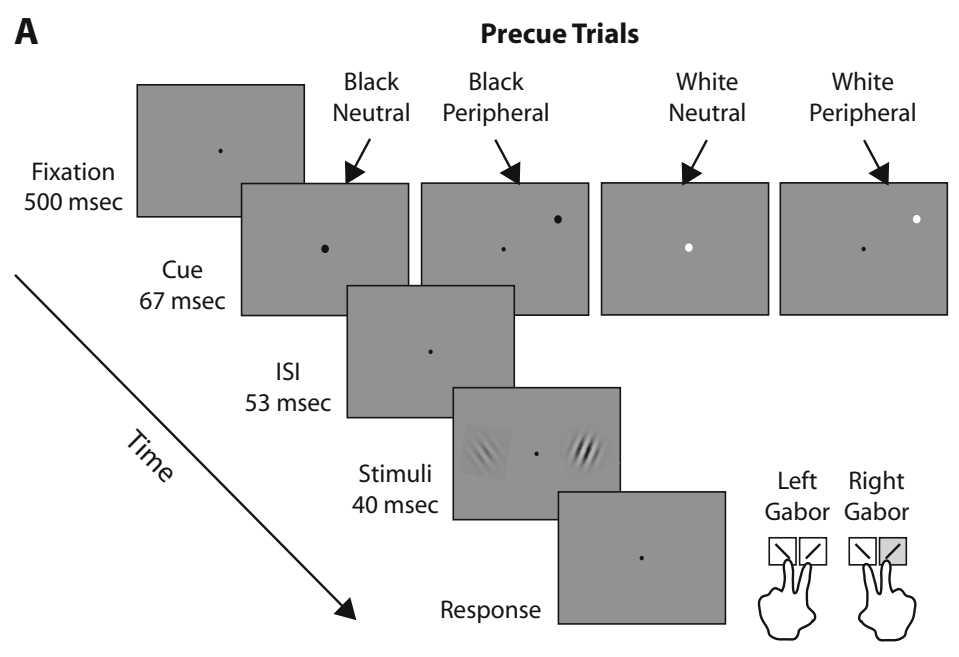

B

Postcue Trials

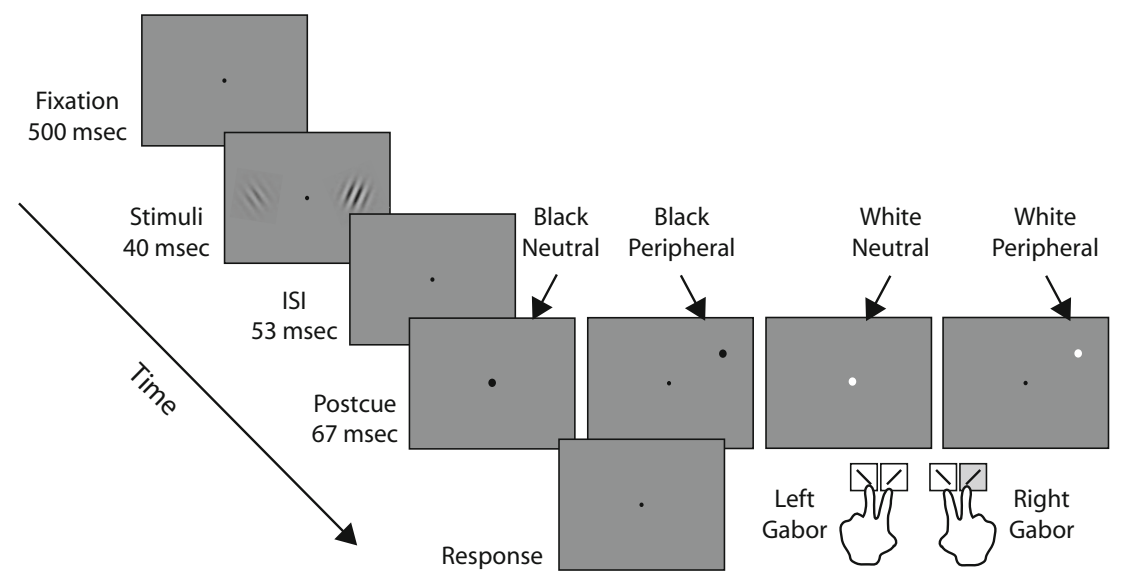

Figure 2. Trial sequences for appearance experiment (Experiment 1, Phase 2). (A) Precue trials: Uninformative cue precedes presentation of stimuli. Cue color, cue type and position, and stimulus contrasts, positions, and orientations were fully randomized. (B) Postcue trials: The trial follows stimulus presentation, with reversed temporal spacing relative to the precue trials. Precue and postcue trials were in separate runs of 1,000 trials, with order counterbalanced across observers.

Phase 2. Separate Weibull functions were fit to individual observers' data for each combination of cue timing (preand post-), cue polarity (black and white), and stimulus cue condition (neutral, standard, and test). The PSEs were derived for each fitted function. We performed within-subjects ANOVAs to check for cue polarity effects. There were no significant main or interaction effects involving cue contrast polarity for the precue [main effect, $F(1,9)=1.7, p>.1$; polarity $\times$ stimulus cue condition, $F(2,18)=2.9, p>.1]$ or the postcue [main effect, $F(1,9)=2.5, p>.1$; polarity $\times$ stimulus cue condition, $F(2,18)=1.6, p>.1]$. This is consistent with the finding that the cuing effects are not due to sensory interactions (Ling \& Carrasco, 2007). Because cue polarity made no difference, the data were collapsed across cue polarity for refitting and further analysis.

The results are summarized in the average appearance psychometric functions for precues and postcues (Fig- ures $4 \mathrm{~A}$ and $4 \mathrm{~B}$, respectively). As expected in the neutral condition, for both the precues and postcues the PSE indicates that when the test and standard were both physically $21 \%$ in contrast, observers were equally likely to report each stimulus as appearing higher in contrast. Precuing the test stimulus reduced the test contrast required to match the standard. Conversely, precuing the standard stimulus increased the test contrast required to match the standard [one-way ANOVA on stimulus cue condition: $F(2,18)=$ $44.8, p<.001$; see Figure 4A].

These cuing effects were completely absent in the postcue condition $[F(2,18)<1]$. As can be seen in Figure 4B, there is no statistically significant or meaningful difference between the psychometric functions according to the position of the postcue.

Average discrimination for all observers across all trials was close to ceiling ( $93 \%$ for the test, neutral, and stan- 


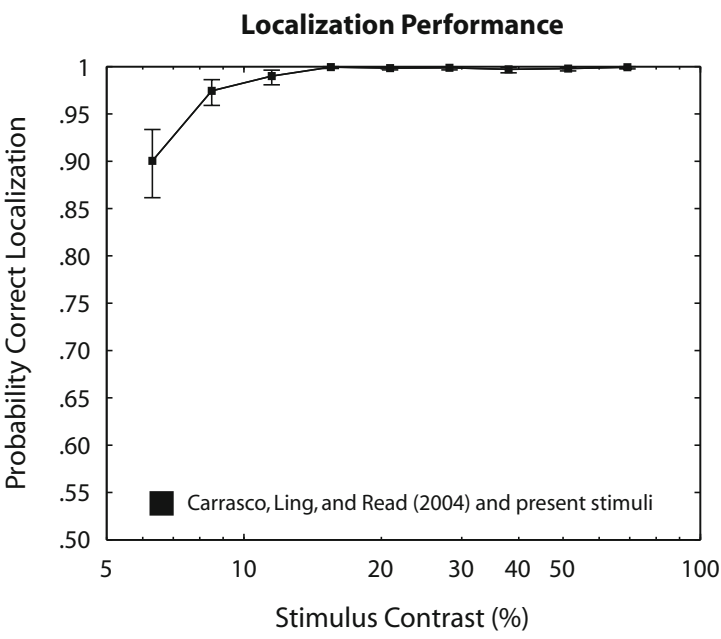

Figure 3. Localization performance (Phase 1). Probability of correct localization, for 10 observers participating in an appearance task (Phase 1), of a single stimulus on the right or left of fixation (vertical axis) versus a stimulus's Michelson contrast. Contrasts and all other stimulus parameters in the localization phase were the same as in the appearance task. Error bars are \pm 1 SEM.

dard cue conditions, no significant difference), and exceeded $90 \%$ for all but our two lowest stimulus contrasts. The orientation discrimination was easy for our observers, which eliminated any opportunity for the peripheral cue to affect performance. At lower test stimulus contrasts in the range for which orientation discrimination may be more difficult, observers are increasingly likely to choose the standard stimulus as higher contrast. The number of trials with orientation reports for these stimuli becomes very small, precluding their use for analysis; for Experiment 1, our 10 observers together reported on the $8.5 \%$ contrast test stimulus on 112 trials in total for all three cue conditions, and 80 trials for the $6.3 \%$ contrast test stimulus.

\section{EXPERIMENT 2}

To attempt to understand the differences reported by Prinzmetal et al. (2008) and by Carrasco, Ling, and Read (2004), we conducted an experiment in which we assessed localization performance for the stimuli used by Prinzmetal et al. (2008). We tested 10 observers (undergraduate and graduate students at NYU) following the procedure used in Phase 1 of Experiment 1, using the stimulus size and spatial frequency reported in Figure 2 of Prinzmetal et al.'s (2008, accepted version) study: size, 1.05; spatial frequency, $11 \mathrm{cpd}$; eccentricity, $1.87^{\circ}$; interstimulus distance, $3.7^{\circ}$ (Phase 1). Half of these observers had participated in both phases of Experiment 1 (Phase 1, followed by Phase 2).

Figure 5A shows the mean localization data for the 10 observers viewing these 11-cpd stimuli in Experiment 2 (triangles), compared with the localization data from Experiment 1 , Phase 1 (squares). The results clearly indicate that the difference in stimulus parameters drastically affects visibility. With this stimulus configuration, observers were at chance for localizing the stimulus until the contrast reached about $40 \%$, which is above the highest contrast stimulus in Prinzmetal et al.'s (2008) Experiment 1 , and only reached $90 \%$ localization performance at $80 \%$ contrast. These parameters likely led to their observers' comments that they could not see the stimuli, even when the Michelson contrast was $40 \%-50 \%$. This poor localization performance indicates that the stimuli in Prinzmetal et al. (2008) were indeed near threshold, and
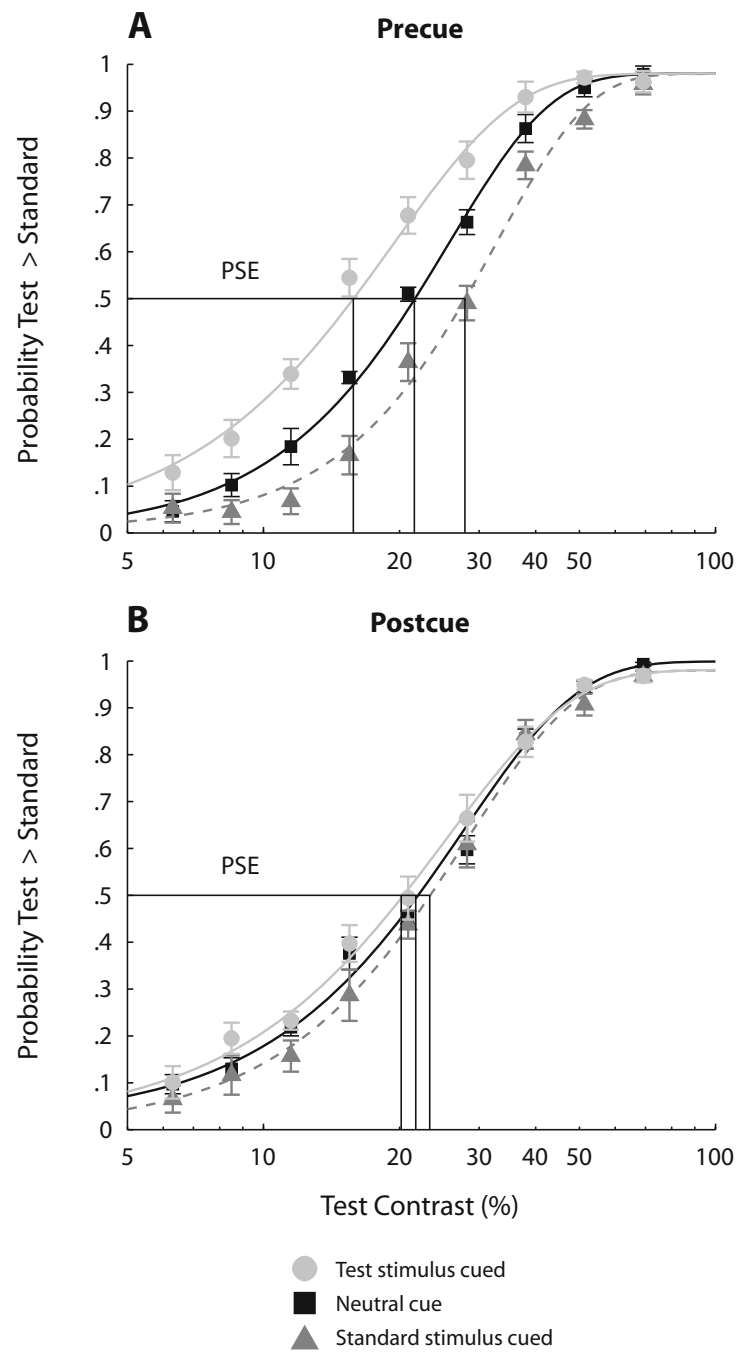

Figure 4. Appearance results (Experiment 1, Phase 2). We show results pooled across 10 observers. (A) Precue trials: The psychometric function shifts toward lower test contrast when the test is cued, and toward higher test contrast when the standard is cued, indicating that transient attention increases the apparent contrast of the cued stimulus. (B) Postcue trials: The psychometric functions for test-cued and standard-cued conditions are not statistically different from the neutral cue condition. Error bars are \pm 1 SEM. 
A

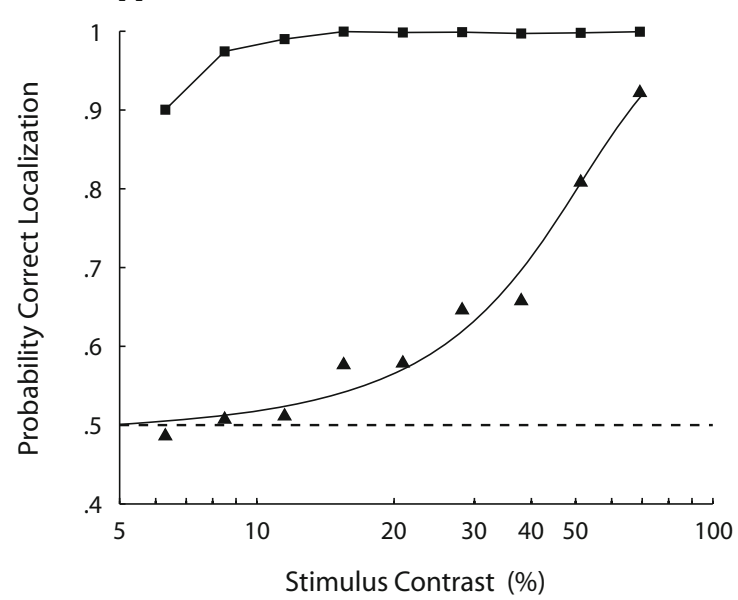

B

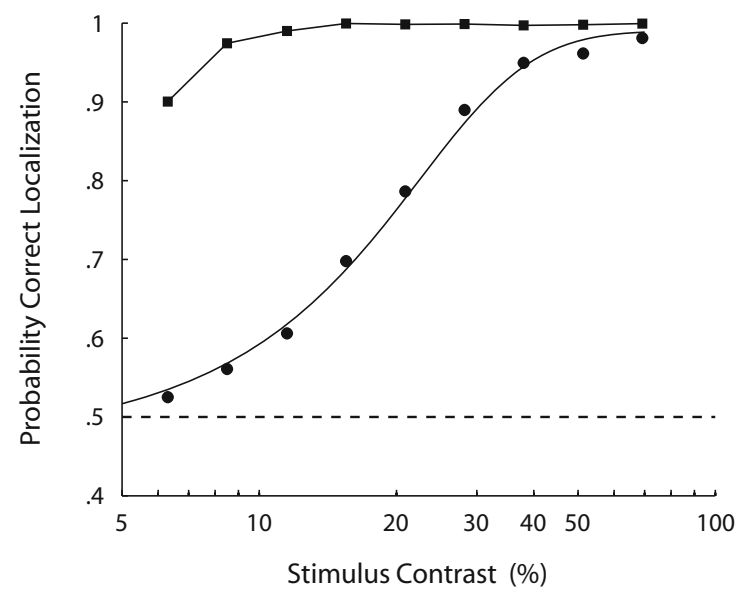

Carrasco, Ling, and Read (2004) and present stimuli, 4 cpd
Prinzmetal et al. (2008) stimuli, $11 \mathrm{cpd}$
Prinzmetal et al. (2008) stimuli, $7 \mathrm{cpd}$

Figure 5. Localization performance with the Prinzmetal et al. (2008) stimuli: Probability of correct localization of a single stimulus on the right or left of fixation (vertical axis) versus a stimulus's Michelson contrast. (A) Triangles indicate performance for 10 observers with 11-cpd, $1.05^{\circ}$ visual angle Gabors, as reported by Prinzmetal et al. (2008, accepted version). (B) Circles indicate performance for 9 observers with 7 -cpd, $1.05^{\circ}$ visual angle Gabors, as reported by Prinzmetal et al. (2008, published version). For comparison, we include the localization performance for 10 observers with $4-c p d, 2^{\circ}$ visual angle Gabors at $4^{\circ}$ eccentricity, as used by Carrasco, Ling, and Read (2004; squares).

in this case it is possible that observers adopted a bias-like strategy, in which they simply reported the side with the cue because that was the only object they perceived on the screen.

Just before submitting our reply, we were informed that the stimulus parameters reported in the accepted manuscript were incorrect, and that the published version would report a stimulus size of 1.55 resulting in $7 \mathrm{cpd}$. According to Prinzmetal (personal communication, 2008, via Action Editor),

the peculiar way in which he measured the size of the Gabor stems from the fact that he was working with a screen snapshot of a stimulus. In other words, he did not generate the Gabor by specifying cycles/degree and standard deviation of the Gaussian. He created [the stimulus depicted in his] Figure 2 by converting the stimulus into a matrix of gray values. He then pasted the middle row of the matrix in delta graph. He measured the physical extent of the stimulus by marking where the gray values of the Gabor matched the gray values of the background, and the distance between these points, orthogonal to the grating, was 1.55 degrees, not all of which may be visible.

This explanation is confusing to us. If, as it appears, the snapshot was a square frame containing a $45^{\circ}$ rotated stimulus, then the profile orthogonal to the grating must be along the matrix diagonal, not the middle row. Our interpretation of the quote in the paragraph above is that the $1.55^{\circ}$ measurement comes from a diagonal measurement of the square matrix in which the Gabor was embedded. Were this the explanation for this reported measure, the conventional size of this matrix would be $1.55 / \sqrt{ } 2=1.09$, which is close to the $1.05^{\circ}$ reported originally. Note also that if the stimuli were $1.55^{\circ}$, given the peak contrasts Prinzmetal et al. (2008) reported in Table 1, the Barlow unit values in the same table would be incorrect, since these values are consistent with inputting to the formula a stimulus size of 1.05 but inconsistent with a stimulus size of 1.55 .

Although the reported Barlow units indicated a stimulus diameter of $1.05^{\circ}$, spatial frequency does not affect contrast energy and cannot be deduced in the same manner. Because Prinzmetal et al.'s (2008) Figure 2 indicated $11 \mathrm{cpd}$, whereas the text reported $7 \mathrm{cpd}$, we decided to test with 7-cpd stimuli the same observers who had participated in the 11-cpd condition. With this stimulus configuration, observers reached $90 \%$ localization performance at about $40 \%$ contrast (Figure 5B). This poor localization performance indicates that the stimuli in Prinzmetal et al. (2008) were indeed of significantly lower visibility than the stimuli of Carrasco, Ling, and Read (2004). In this case, given location uncertainty, it is also possible that observers adopted a bias-like strategy in which they were more likely to report the side containing the cue. However, as shown in Experiment 1, Phase 1, this was not the case in Carrasco, Ling, and Read.

\section{DISCUSSION}

Prinzmetal et al. (2008) suggest that the results of Carrasco, Ling, and Read (2004) arose not from attentional factors, but rather because observers were simply biased toward the cued location when the stimuli were near threshold. Here, we have outlined the key methodological differences between these two studies that are likely responsible for the different results. In addition, the local- 
ization performance for the stimulus parameters used by Carrasco, Ling, and Read (Figure 3), and the comparison for stimulus parameters used by Prinzmetal et al. (2008) and by Carrasco, Ling, and Read (Figure 5), unequivocally show that the stimulus contrasts we used here (as well as in Carrasco, Ling, \& Read, 2004, and in Ling \& Carrasco, 2007) are suprathreshold, not near threshold or of low visibility, and are thus immune from the visibility-based cue-bias hypothesis laid forth by Prinzmetal et al. (2008). Furthermore, we have provided empirical evidence showing that, whereas a precue affects contrast appearance, a postcue does not (Figure 4), providing additional evidence against a cue-bias explanation for our results.

\section{Ruling Out Alternative Explanations for the Cuing Effect}

The bias hypothesis put forth by Prinzmetal et al. (2008) cannot account for several control experiments that had been conducted to rule out cue or response bias. Here we outline those experiments to underscore how difficult it would be to provide a convincing "response bias" model that would explain all these results. Note that each of these controls deals with contrast appearance studies as well as with studies in other visual dimensions.

Postcue versus precue. In previous studies dealing with perceived contrast of suprathreshold stimuli (Carrasco, Ling, \& Read, 2004; Fuller et al., 2008; Ling \& Carrasco, 2007), we used many controls (see below), but we did not apply the postcue control to the contrast appearance studies. This control was introduced in a study dealing with the effects of transient attention on appearance of characteristics related to spatial resolution - perceived spatial frequency and perceived gap size. Given that the spatial and temporal contiguity between cue and stimulus were the same, if the effect of appearance were due to a cue bias, the pattern of results would be the same, whether the cue was presented before or after the stimuli. The results were clear-cut: Precuing, but not postcuing, resulted in an appearance effect (Gobell \& Carrasco, 2005). Subsequently, others have also successfully used a postcue control in appearance studies (Anton-Erxleben et al., 2007; Turatto et al., 2007). The results of all these control experiments are consistent with an fMRI study investigating the neural basis of transient attention, in which precuing, but not postcuing, the target location increased stimulus-evoked response in corresponding retinotopic striate and extrastriate areas (Liu et al., 2005).

Using low-visibility stimuli in conjunction with this postcue control, Prinzmetal et al. (2008) reported that they got comparable results whether the cue appeared before (Experiment 1) or after (Experiment 4) the stimuli. This result is likely due to the low visibility of their stimuli. Here, we show a clear dissociation between conditions when the suprathreshold stimuli are precued and when they are postcued; although there is a clear shift in perceived contrast for the precue, the postcue shows no such shift (Figure 4). These results unequivocally support an appearance rather than a cue-bias account.

Reversed direction of the task question. We have shown that when observers were asked to report the orien- tation of the stimulus of lower, rather than higher, apparent contrast, observers chose the cued test stimulus less frequently (Carrasco, Ling, \& Read, 2004; Ling \& Carrasco, 2007). Had the appearance results been due to a cue bias, observers would have chosen the cued stimulus more often than the other stimulus regardless of the direction of the task. Reversing the instructions has been a successful control in numerous appearance studies of contrast (Carrasco, Ling, \& Read, 2004; Ling \& Carrasco, 2007), spatial frequency (Gobell \& Carrasco, 2005), color saturation (Fuller \& Carrasco, 2006), flicker rate (Montagna \& Carrasco, 2006), size of a moving object (Anton-Erxleben et al., 2007), and speed (Turatto et al., 2007). Furthermore, the reverse instruction has also been used successfully when observers perform a comparative appearance judgment and orientation discrimination, as well as when they perform the comparative appearance judgment only (AntonErxleben et al., 2007; Carrasco, Ling, \& Read, 2004).

Prinzmetal et al. (2008) assert that these reverseinstruction results can be explained by observers still having a bias for the cued stimulus if the stimuli are at or below threshold but somehow "reversing" the decision before responding. Given that the stimuli we used are suprathreshold (Figure 3) in the present study, as well as in all other studies mentioned in the previous paragraph dealing with a variety of dimensions (spatial frequency, speed, flicker rate, and object size), Prinzmetal et al. (2008)'s interpretation is not applicable.

Performance. The signature of attentional modulation on behavior is an improvement in performance for an attended stimulus. Prinzmetal et al. (2008) claim that Carrasco, Ling, and Read (2004) did not report a performance measure, which is not true. We reported that attention "improved performance by $10 \%$ at PSE, and ranged from $18 \%$ at lower contrasts to $4 \%$ at higher contrasts where performance approached asymptote" (Carrasco, Ling, \& Read, 2004, p. 310).

Other studies dealing with appearance-contrast (Fuller et al., 2008; Ling \& Carrasco, 2007), saturation (Fuller \& Carrasco, 2006), motion coherence (Liu et al., 2006), and size of a moving object (Anton-Erxleben et al., 2007) - have also documented a concurrent effect of attention on appearance and on performance level. Performance in the studies dealing with contrast and saturation has been assessed with an orientation discrimination task (Carrasco, Ling, \& Read, 2004; Fuller \& Carrasco, 2006; Fuller et al., 2008; Ling \& Carrasco, 2007), whereas performance in studies dealing with motion has been assessed with a motion direction discrimination task (AntonErxleben et al., 2007; Liu et al., 2006). Improvements in such performance-based tasks indicate that exogenous attention has been successfully engaged to a peripheral location. Because cue location and stimulus orientation are uncorrelated, concurrent improvements at the cued locations and impairments at the uncued locations further show that the appearance results are not due to response bias. This has been the case for several studies in which the stimuli have been titrated to individual observer performance thresholds in the $75 \%-80 \%$ correct range, allowing room for both improvements and impairments; 
see Fuller and Carrasco (2006, p. 4042), Liu et al. (2006, pp. 1093-1094), and Fuller et al. (2008, pp. 9-10).

Prinzmetal et al. (2008) report higher accuracy for the uncued than for the cued stimuli for an orientation discrimination task. They acknowledge that this was a surprising result and attribute it to their cue-bias hypothesis. This finding is inconsistent with the vast majority of studies assessing the effect of exogenous attention on orientation discrimination (e.g., Cameron, Tai, \& Carrasco, 2002; Carrasco, Giordano, \& McElree, 2004, 2006; Carrasco et al., 2000; Dosher \& Lu, 2000a, 2000b; Fuller et al., 2008; Ling \& Carrasco, 2006a, 2007; Lu \& Dosher, 1998, 2000; Pestilli \& Carrasco, 2005; Pestilli, Viera, \& Carrasco, 2007). But more importantly, it questions whether their results are due to the attentional manipulation or to a sensory interaction between cue and stimulus. Their stimulus configuration was such that the distance between the centers of the cue and target was presumably very small. Although Prinzmetal et al. (2008) do not explicitly report this distance, we presume that the distance was around $0.75^{\circ}$, since it appears that their stimuli were scaled down to roughly half the size of ours (the distance between the centers of the cue and target was $1.5^{\circ}$ ). It is possible that this cue-to-stimulus distance was too close, and the peripheral cue they used in their experiment actually masked the cued stimulus, which would explain their slight decrease in performance at the cued location. Moreover, the size of the exogenous cue, although not specified, was presumably very small as well. Given that their stimuli were all scaled down by about half of those used in Carrasco, Ling, and Read (2004) their cue size was approximately $0.15^{\circ}$, which perhaps was neither large nor salient enough to grab observers' transient attention.

To be able to conclude that there is no effect of attention on appearance, it is important to show that attention was manipulated effectively. We have previously argued that when attention does not alter appearance, it is necessary to verify that attention alters performance in tasks mediated by the same stimuli (e.g., Carrasco, in press). For instance, we have reported that attention did not alter appearance of color hue, yet it did improve orientation discrimination performance for stimuli of the same hue (Fuller \& Carrasco, 2006). Thus, we could rule out the possibility that the lack of an appearance effect would result from an ineffective attentional manipulation. In contrast, given the higher accuracy for the uncued than the cued location, Prinzmetal et al. (2008) did not have evidence that their attentional manipulation was effective. Moreover, the finding that attention alters saturation appearance, but not hue, supports the idea that attention alters appearance and that the effects are not due to a cue bias, which would lead to the same effect regardless of visual dimension (Carrasco, in press; Fuller \& Carrasco, 2006).

Lengthened interval between the cue and target. Due to the ephemeral nature of transient attention, whose effect peaks at $\sim 120 \mathrm{msec}$ and decays rapidly (Cheal \& Lyon, 1991; Nakayama \& Mackeben, 1989; Remington, Johnston, \& Yantis, 1992), a lengthened interval between the cue and target should eliminate any effect that it may have on perception, and any residual effect would be attributed to a cue bias. When the cue preceded the stimuli by $500 \mathrm{msec}$, neutral and peripheral conditions did not differ. Appearance studies of contrast (Carrasco, Ling, \& Read, 2004; Fuller et al., 2008; Hsieh et al., 2005), motion coherence (Liu et al., 2006), and speed (Turatto et al., 2007) show that when transient attention is no longer active, stimulus appearance is not altered.

Location asymmetry. The magnitude of the appearance effect varies at different locations of the visual field; the effect is greater on the lower than on the upper vertical meridian (Fuller et al., 2008). We have proposed a model based on signal detection theory to explain this differential effect by unequal attention modulation at isoeccentric locations on the vertical meridian. Of specific relevance is the fact that response bias cannot explain this difference in attentional effects (Fuller et al., 2008). If anything, a cue bias would predict the effect of attention to be more pronounced on the upper than the lower vertical meridian, since contrast sensitivity is lower in the former than in the latter (Cameron et al., 2002; Carrasco, Talgar, \& Cameron, 2001).

Evidence across visual domains. Finally, there is an obvious but unanswered question: How would a cue bias hypothesis contingent on stimuli being near threshold (Prinzmetal et al., 2008) be able to explain appearance findings with other suprathreshold stimuli, such as spatial frequency (Gobell \& Carrasco, 2005), motion (Liu et al., 2006), flickering gratings (Montagna \& Carrasco, 2006), saturation (Fuller \& Carrasco, 2006), speed (Turatto et al., 2007), and size of a moving stimulus (Anton-Erxleben et al., 2007)? Particularly relevant for this reply are other studies of exogenous attention and perceived contrast (Hsieh et al., 2005), including those manipulating cue polarity (Ling \& Carrasco, 2007) and location along the vertical meridian (Fuller et al., 2008). Moreover, how could a visibility-based cue-bias hypothesis account for studies showing that the appearance effect on spatial frequency (Gobell \& Carrasco, 2005) and on flicker rate (Montagna \& Carrasco, 2006) was not mediated by contrast?

To conclude, the question of whether the method used by Carrasco, Ling, and Read (2004) is susceptible to response bias has been examined by all the controls mentioned above (not just the ones mentioned by Prinzmetal et al., 2008). These controls have effectively ruled out the possibility of response bias in contrast appearance, as well as in many other visual dimensions, and any new claim of response bias should address all these control experiments adequately.

\section{Location Uncertainty}

Prinzmetal et al. (2008) also invoke location uncertainty to explain our previous findings. However, we have shown here that the stimuli in Carrasco, Ling, and Read (2004) are suprathreshold (Figure 3) and that there is no location uncertainty. Note that an explanation based on either location uncertainty or cue bias would predict the largest effect for the lowest stimulus contrast, but this was not the case. Finally, location uncertainty models typically require a target stimulus to be in the design, but there is no designated target in the appearance paradigm; observers select the stimulus whose orientation they discriminate.

Prinzmetal et al. (2008) further suggest that location uncertainty may be responsible for the behavioral effects 
observed in an fMRI study by Liu et al. (2005). However, key aspects of this study are not mentioned: First, observers performed an orientation discrimination task on suprathreshold stimuli, and location uncertainty is relevant for detection but not discrimination of such stimuli (Foley \& Schwarz, 1998). Second, the main point of this study was that exogenous attention increased the retinotopic BOLD activity for precued locations, not for postcued locations, thus ruling out the sensory contribution of the cue. No uncertainty model predicts such changes of BOLD in visual cortex.

Prinzmetal et al. (2008) also cite a study by Cameron et al. (2002) as further evidence for a location uncertainty explanation of the effects of transient attention. This study assessed the effects of transient attention by comparing the stimulus contrast necessary for observers to perform an orientation discrimination task (Nachmias, 1967), with or without the aid of transient attention. Regarding this study, Prinzmetal et al. (2008) speculate that "on trials when the distractor was cued, performance would have been worse than when the target was cued because the observer was biasing the response on the wrong stimulus." However, this speculation is groundless, since the purpose of Cameron et al. was to exclude factors of external noise reduction, and therefore only one suprathreshold target appeared in the display, in the absence of distractors or masks. Furthermore, Cameron et al. showed that the benefit of transient attention was comparable in two orientation discrimination conditions $\left( \pm 15^{\circ}\right.$ and $\pm 4^{\circ}$ tilt $)$, even though localization performance was higher on the localization task for the fine discrimination targets, for which the stimulus contrast was higher (Cameron et al., 2002, Figure 10). These results showed that the benefit of attention could not solely be explained by a reduction of location uncertainty.

More relevant for Prinzmetal et al.'s (2008) argument on location uncertainty are studies with uninformative peripheral precues (Pestilli \& Carrasco, 2005; Pestilli et al., 2007). In these studies, we presented two simultaneous stimuli and included a response cue so that location uncertainty regarding which stimuli observers should report was eliminated (Dosher \& Lu, 2000b). Consistent with Liu et al. (2005), those studies showed that contrast sensitivity is enhanced at the cued location and diminished at the uncued location (Pestilli \& Carrasco, 2005; Pestilli et al., 2007).

Prinzmetal et al. (2008) also mention a detection study in which observers were more accurate in a detection task on the cued than on the uncued location only when the fiducial markers indicating target location were not present- that is, when there was location uncertainty (Gould, Wolfgang, \& Smith, 2007). Indeed, only a few studies have reported effects of attention on detection (e.g., Carrasco et al., 2000; Smith, 2000). Prinzmetal et al. (2008) claim that whereas endogenous attention can affect performance, exogenous attention has no influence on accuracy. However, this cannot be generalized to discrimination studies, in which effects of attention on performance have been found for both low- and high-contrast stimuli. There are many discrimination studies documenting the effects of exogenous attention on performance, when location un- certainty is not an issue (e.g., Baldassi \& Burr, 2000; Carrasco et al., 2000; Carrasco, Williams, \& Yeshurun, 2002; Dosher \& Lu, 2000a, 2000b; Fuller et al., 2008; Ling \& Carrasco, 2006a, 2006b, 2007; Lu \& Dosher, 1998, 2000; Morgan, Ward, \& Castet, 1998; Pestilli \& Carrasco, 2005; Pestilli et al., 2007; Talgar, Pelli, \& Carrasco, 2004; Yeshurun, Montagna, \& Carrasco, 2008).

In conclusion, the aforementioned evidence suggests that location uncertainty is relevant for Prinzmetal et al. (2008), who used near-threshold or low-visibility stimuli (Figure 5), but neither for the present study nor for the Carrasco, Ling, and Read (2004), Ling and Carrasco (2007), and Fuller et al. (2008) studies, which used suprathreshold stimuli (Figure 3).

\section{Perceived Brightness: Tsal, Shalev, Zakay, and Lubow (1994) and Schneider (2006)}

Prinzmetal et al. (2008) refer to two studies dealing with perceived brightness and draw comparisons with the results of Carrasco, Ling, and Read (2004) on perceived contrast. Here we detail the differences with these studies and explain why we consider such direct comparisons inappropriate.

Tsal et al. (1994). Tsal et al. (1994) reported that attention reduces perceived brightness contrast (but see Prinzmetal, Nwachuku, Bodanski, Blumenfield, \& Shimizu, 1997, for an alternative explanation). Observers were asked to make a comparison judgment between the target and one of four test patterns held in memory, thus forcing observers to rely on a possibly biased categorical memory representation to make their responses (Experiments 1-3). In Experiment 4, the authors eliminated postperceptual biases that could have affected the first three experiments. They conclude that the attended stimulus was perceived as brighter or darker than was the unattended stimulus when it appeared on a white or a black background, respectively.

Prinzmetal et al. (2008) inaccurately claim that the paradigm in Tsal et al. (1994) was "identical" to the one used in Carrasco, Ling, and Read (2004). The paradigms used in the two studies actually differ in fundamental ways regarding both task and stimulus.

The visual domain being investigated fundamentally differed between Tsal et al. (1994) and Carrasco, Ling, and Read (2004). Tsal et al. asked observers to judge the relative brightness of two squares presented on a (black or white) homogeneous background. Note that luminance and contrast processing are largely independent in natural images, as are the mechanisms of luminance-gain control and contrast-gain control in the early visual system (Mante, Frazor, Bonen, Geisler, \& Carandini, 2005). Indeed, Tsal et al. stated, "The present findings do not necessarily demonstrate a direct effect of attention on contrast perception. ... It is more likely that attention interferes at a later stage by minimizing the effect of these processes on the perceptual representation of brightness" (p. 890). Carrasco, Ling, and Read asked observers to judge the orientation of the higher/lower contrast stimulus, not brightness.

Because Tsal et al. (1994) were interested in perceived brightness, there were profound differences in the stimuli used. Tsal et al. used $0.69^{\circ}$ squares as stimuli, presented at two opposite positions of eight possible positions around 
three circles $\left(\sim 10^{\circ}, 12^{\circ}\right.$, or $15^{\circ}$ eccentricity). Half the trials were presented on a white background, and the others were presented on a black background. Carrasco, Ling, and Read (2004) used $2^{\circ}$ Gabor patches $\left(2^{\circ} \times 2^{\circ}\right.$ sinusoidal gratings enveloped by a Gaussian), presented to the left and right of fixation at $4^{\circ}$ along the horizontal meridian on a gray background.

Finally, the paradigms used in the two studies are very different as well. Tsal et al. (1994) asked observers to make direct appearance judgments; observers were asked to indicate which square was brighter or darker (between subjects). Carrasco, Ling, and Read (2004) asked observers to make an orientation judgment, contingent on relative appearance. The design emphasized to observers the orientation judgment, when in reality we were interested in their contrast judgments. In addition, assessing orientation discrimination meant there was an objective index of the effectiveness of the attention manipulation.

Given all these differences, there is no reason to infer that the attention effects would necessarily be parallel in Tsal et al. (1994) and in Carrasco, Ling, and Read (2004). We acknowledge the possibility that attention exerts a different effect on perceived brightness (Tsal et al., 1994) compared with perceived contrast (present study and Carrasco, Ling, \& Read, 2004; Fuller et al., 2008; Hsieh et al., 2005; Ling \& Carrasco, 2007).

Schneider (2006). In another study, Schneider (2006) reported that peripheral cues increase perceived brightness only at stimulus levels near detection threshold, more so for white than for black cues. He proposed that the findings of Carrasco, Ling, and Read (2004) regarding perceived contrast might not be due to attention increasing apparent contrast, but rather due to sensory interactions between the cue and stimuli, particularly at higher stimulus contrasts. Ling and Carrasco (2007), in a reply to Schneider, showed that his results on brightness contrast of a luminance disk cannot be generalized to those of luminance contrast in Carrasco, Ling, and Read.

Prinzmetal et al. (2008) refer to Schneider's (2006) findings as supporting the hypothesis that involuntary attention increases contrast, but only for low contrast stimuli. Although they briefly refer to Ling and Carrasco (2007), they do not mention several important points of this reply, which indicate that the findings of Schneider are not applicable to the findings of Carrasco, Ling, and Read (2004).

Ling and Carrasco (2007) acknowledged the possibility that attention exerts a different effect on perceived brightness (as investigated by Schneider, 2006) compared with perceived contrast (as investigated in the present study, and by Carrasco, Ling, \& Read, 2004; Fuller et al., 2008; Hsieh et al., 2005; Ling \& Carrasco, 2007). However, this conclusion is limited by the fact that the peripheral cue (black or white cue rings surrounding the upcoming stimulus location) used in Schneider's study has also been shown to act as a forward, paracontrast mask (Breitmeyer et al., 2006; Ogmen, Breitmeyer, \& Melvin, 2003), which could extinguish any attentional effects on perceived brightness. Thus, because the precue could have served double duty as both an attentional cue and an unintended paracontrast mask, it is possible that Schneider's results are due to sensory con- tamination of the stimulus by the precue. Indeed, masks with characteristics similar to Schneider's precue can lead to similar differential effects depending on the luminance of the mask, with white rings increasing apparent brightness more than do black rings (Breitmeyer et al., 2006).

Schneider (2006) predicted that reversing the cue's luminance polarity should lead to differential cuing effects in Carrasco, Ling, and Read (2004) paradigm. However, when we tested this prediction, both black and white cues increased the apparent contrast to the same degree, thus confirming that the cue effect is due to attention rather than to sensory factors (Ling \& Carrasco, 2007). We replicated this finding in the present study.

Of critical importance for the present reply is the fact that using the same paradigm and parameters as Carrasco, Ling, and Read (2004; Experiment 2), Schneider (2006) has recently replicated our high-contrast findings (personal communication, 2008; Schneider \& Komlos, 2008), although in his talk he concluded that attention does not alter appearance, but rather influences a decisional stage. However, on the basis of his replication of our findings, and consistent with our previous studies, Schneider now concludes that the results are not due to sensory interactions between the cue and stimuli or cue bias (as claimed by Schneider, 2006, and Prinzmetal et al., 2008).

\section{Attention and Veridicality}

Prinzmetal et al. (2008) state, "Attention should make our interactions with the world more successful, and it can only do this by making our perceptions more accurate, not by shifting them. ... Like lightness constancy, attention should lead to a more veridical perception of the world. ... To be a useful mechanism in an evolutionary sense, attention should not lead us astray" (p. 1149).

We disagree with this idea for the following reasons.

1. Lightness constancy is actually an example of a perceptual phenomenon where our visual system is not acting veridically, but rather altering our percept on the basis of contextual cues (e.g., Adelson, 2000; Gilchrist, 1988).

2. Several studies have shown that attention can actually impair our perception (Carrasco, Loula, \& Ho, 2006; Ling \& Carrasco, 2006b; Talgar \& Carrasco, 2002; Yeshurun, 2004; Yeshurun \& Carrasco, 1998, 2000, 2008; Yeshurun \& Levy, 2003; Yeshurun et al., 2008) and enhance aftereffects (e.g., Alais \& Blake, 1999; Bahrami, Carmel, Walsh, Rees, \& Lavie, 2008; Ling \& Carrasco, 2006b; Liu, Larsson, \& Carrasco, 2007; Spivey \& Spirn, 2000).

3 . There is a vast literature demonstrating that the visual system operates on the retinal image so as to maximize its usefulness to the perceiver, often producing nonveridical percepts. The visual system does not provide an internal one-to-one copy of the external visual world; rather, it optimizes processing resources by enhancing relevant features of our visual environment at the expense of a sketchy representation of less relevant aspects. Attention is one pervasive example of this perceptual optimization: Attention augments perception by optimizing our representation of sensory input, and by emphasizing relevant details at the expense of a faithful representation of the sensory input (Treue, 2004). 


\section{CONCLUSION}

It is likely that the appearance enhancement reported here and in previous studies (Carrasco, Ling, \& Read, 2004; Fuller et al., 2008; Ling \& Carrasco, 2007) accompanies the increased contrast sensitivity observed in many psychophysical studies. The conclusion that attention increases apparent contrast supports a "linking hypothesis," which states that the attentional enhancement of neural firing is interpreted as if the stimulus had a higher contrast. Converging evidence from neurophysiological, psychophysical, and neuroimaging studies supports this proposal (Carrasco, 2006; Luck, 2004; Reynolds \& Chelazzi, 2004; Treue, 2004).

Using the appearance paradigm introduced by Carrasco, Ling, and Read (2004), it has been found that attention alters our subjective impression of many dimensions of spatial and temporal vision, mediated by the ventral and dorsal streams, respectively: contrast (Carrasco, Ling, \& Read, 2004; Fuller et al., 2008; Hsieh et al., 2005; Ling $\&$ Carrasco, 2007; present study), spatial frequency and gap size, both related to spatial resolution (Gobell \& Carrasco, 2005), color saturation (but not hue; Fuller \& Carrasco, 2006), and perceived size of moving visual patterns (Anton-Erxleben et al., 2007), as well as flicker rate (Montagna \& Carrasco, 2006), motion coherence (Liu et al., 2006), and perceived speed (Turatto et al., 2007).

By showing that the spatial deployment of attention leads to a change in phenomenological experience, these studies confirm the intuition of William James (1890/1950), who proposed that attention could intensify the sensory impression of a stimulus. Attention not only affects how we perform in a visual task, it also affects what we see and experience. Consistent with previous studies (Carrasco, Ling, \& Read, 2004; Fuller et al., 2008; Hsieh et al., 2005; Ling \& Carrasco, 2007), here we show that attention increases perceived contrast of suprathreshold stimuli, for which there is no location uncertainty, and we rule out a cue-bias explanation of the results.

\section{AUTHOR NOTE}

The authors thank Yaffa Yeshurun, Taosheng Liu, and members of the Carrasco lab for their valuable comments and suggestions. This research was funded by National Institute of Health Grant RO1 EY016200-01A2 to M.C. Correspondence concerning this article should be addressed to M. Carrasco, Department of Psychology, New York University, 6 Washington Pl., New York, NY 10003 (e-mail: marisa.carrasco@nyu.edu).

\section{REFERENCES}

Adelson, E. H. (2000). Lightness perception and lightness illusions In M. Gazzaniga (Ed.), The new cognitive neurosciences ( 2 nd ed., pp. 339-351). Cambridge, MA: MIT Press.

Alais, D., \& Blake, R. (1999). Neural strength of visual attention gauged by motion adaptation. Nature Neuroscience, 2, 1015-1018.

Anton-Erxleben, K., Henrich, C., \& Treue, S. (2007). Attention changes perceived size of moving visual patterns. Journal of Vision, 7(11, Art. 5), 1-9

Bahrami, B., Carmel, D., Walsh, V., Rees, G., \& Lavie, N. (2008). Unconscious orientation processing depends on perceptual load. Journal of Vision, 8(3, Art. 13), 1-10.

BALDASSI, S., \& BURR, D. C. (2000). Feature-based integration of orientation signals in visual search. Vision Research, 40, 1293-1300.

Brainard, D. H. (1997). The Psychophysics Toolbox. Spatial Vision, 10, 433-436.
Breitmeyer, B. G., Kafaligonul, H., Ogmen, H., Mardon, L., TODD, S., \& ZIEGLER, R. (2006). Meta- and paracontrast reveal differences between contour- and brightness-processing mechanisms. Vision Research, 46, 2645-2658.

Buracas, G. T., \& Boynton, G. M. (2007). The effect of spatial attention on contrast response functions in human visual cortex. Journal of Neuroscience, 27, 93-97.

Cameron, E. L., Tai, J. C., \& Carrasco, M. (2002). Covert attention affects the psychometric function of contrast sensitivity. Vision Research, 42, 949-967.

CARrasco, M. (2006). Covert attention increases contrast sensitivity: Psychophysical, neurophysiological, and neuroimaging studies. In S. Martinez-Conde, S. L. Macknik, L. M. Martinez, J. M. Alonzo, \& P. U. Tse (Eds.), Visual perception: Part 1. Fundamentals of vision: Low and mid-level processes in perception (pp. 33-70). Amsterdam: Elsevier.

CARrasco, M. (in press). Visual attention alters appearance: Psychophysical studies of subjective experience. In T. Bayne, A. Cleeremans, \& P. Wilken (Eds.), Oxford companion to consciousness. Oxford: Oxford University Press.

Carrasco, M., Giordano, A. M., \& McElree, B. (2004). Temporal performance fields: Visual and attentional factors. Vision Research, 44, 1351-1365.

Carrasco, M., Giordano, A. M., \& McElree, B. (2006). Attention speeds processing across eccentricity: Feature and conjunction searches. Vision Research, 46, 2028-2040.

Carrasco, M., Ling, S., \& ReAd, S. (2004). Attention alters appearance. Nature Neuroscience, 7, 308-313.

Carrasco, M., Loula, F., \& Ho, Y.-X. (2006). How attention enhances spatial resolution: Evidence from selective adaptation to spatial frequency. Perception \& Psychophysics, 68, 1004-1012.

Carrasco, M., Talgar, C. P., \& Cameron, E. L. (2001). Characterizing visual performance fields: Effects of transient covert attention, spatial frequency, eccentricity, task and set size. Spatial Vision, 15, 61-75.

Carrasco, M., Talgar, C. P., \& Eckstein, M. (2000). Spatial covert attention increases contrast sensitivity across the CSF: Support for signal enhancement. Vision Research, 40, 1203-1215.

Carrasco, M., Williams, P. E., \& Yeshurun, Y. (2002). Covert attention increases spatial resolution with or without masks: Support for signal enhancement. Journal of Vision, 2, 467-479.

Cheal, M., \& Lyon, D. R. (1991). Central and peripheral precuing of forced-choice discrimination. Quarterly Journal of Experimental Psychology, 43A, 859-880.

Dosher, B. A., \& Lu, Z.-L. (2000a). Mechanisms of perceptual attention in precuing of location. Vision Research, 40, 1269-1292.

Dosher, B. A., \& Lu, Z.-L. (2000b). Noise exclusion in spatial attention. Psychological Science, 11, 139-146.

Foley, J. M., \& Schwarz, W. (1998). Spatial attention: Effect of position uncertainty and number of distractor patterns on the thresholdversus-contrast function for contrast discrimination. Journal of the Optical Society of America A, 15, 1036-1047.

Fuller, S., \& Carrasco, M. (2006). Exogenous attention and color perception: Performance and appearance of saturation and hue. Vision Research, 46, 4032-4047.

Fuller, S., Rodriguez, R. Z., \& Carrasco, M. (2008). Apparent contrast differs across the vertical meridian: Visual and attentional factors. Journal of Vision, 8(1, Art. 16), 1-16.

GILCHRIST, A. L. (1988). Lightness contrast and failures of constancy: A common explanation. Perception \& Psychophysics, 43, 415-424.

Gobell, J., \& CARrasco, M. (2005). Attention alters the appearance of spatial frequency and gap size. Psychological Science, 16, 644-651.

Gould, I. C., Wolfgang, B. J., \& Smith, P. L. (2007). Spatial uncertainty explains exogenous and endogenous attentional cuing effects in visual signal detection. Journal of Vision, 7(13, Art. 4), 1-17.

Hsieh, P.-J., Caplovitz, G. P., \& Tse, P. U. (2005). Illusory rebound motion and the motion continuity heuristic. Vision Research, 45, 2972-2985.

HuAng, L., \& DobKins, K. R. (2005). Attentional effects on contrast discrimination in humans: Evidence for both contrast gain and response gain. Vision Research, 45, 1201-1212.

JAMES, W. (1950). The principles of psychology. New York: Holt. (Original work published 1890)

Lee, J., Williford, T., \& Maunsell, J. H. R. (2007). Spatial attention 
and the latency of neuronal responses in macaque area V4. Journal of Neuroscience, 27, 9632-9637.

LinG, S., \& CARrasco, M. (2006a). Sustained and transient covert attention enhance the signal via different contrast response functions. Vision Research, 46, 1210-1220.

LING, S., \& CARRASCO, M. (2006b). When sustained attention impairs perception. Nature Neuroscience, 9, 1243-1245.

Ling, S., \& CARRASCO, M. (2007). Transient covert attention does alter appearance: A reply to Schneider (2006). Perception \& Psychophysics, 69, 1051-1058.

Liu, T., Fuller, S., \& Carrasco, M. (2006). Attention alters the appearance of motion coherence. Psychonomic Bulletin \& Review, 13, 1091-1096.

LiU, T., Larsson, J., \& Carrasco, M. (2007). Feature-based attention modulates orientation-selective responses in human visual cortex. Neuron, 55, 313-323.

Liu, T., Pestilli, F., \& Carrasco, M. (2005). Transient attention enhances perceptual performance and fMRI response in human visual cortex. Neuron, 45, 469-477.

Lu, Z.-L., \& Dosher, B. A. (1998). External noise distinguishes attention mechanisms. Vision Research, 38, 1183-1198.

Lu, Z.-L., \& Dosher, B. A. (2000). Spatial attention: Different mechanisms for central and peripheral temporal precues? Journal of Experimental Psychology: Human Perception \& Performance, 26, 1534-1548.

LucK, S. J. (2004). Understanding awareness: One step closer. Nature Neuroscience, 7, 208-209.

Mante,V., Frazor, R. A., Bonen, V., Geisler, W. S., \& Carandini, M. (2005). Independence of luminance and contrast in natural scenes and in the early visual system. Nature Neuroscience, 8, 1690-1697.

Martinez-Trujillo, J., \& Treue, S. (2002). Attentional modulation strength in cortical area MT depends on stimulus contrast. Neuron, 35, 365-370.

Mayfrank, L., Kimmig, H., \& Fischer, B. (1987). The role of attention in the preparation of visually guided saccadic eye movements in man. In J. K. O'Regan \& A. Levy-Schoen (Eds.), Eye movements: From physiology to cognition (pp. 37-45). Amsterdam: North-Holland.

McGuigan, F. J. (1997). Experimental psychology: Methods of research (7th ed.). Englewood Cliffs, NJ: Prentice Hall.

Montagna, B., \& CARrasco, M. (2006). Transient covert attention and the perceived rate of flicker. Journal of Vision, 6, 955-965.

Morgan, M. J., Ward, R. M., \& CASTET, E. (1998). Visual search for a tilted target: Tests of spatial uncertainty models. Quarterly Journal of Experimental Psychology, 51A, 347-370.

Morrone, M. C., Denti, V., \& Spinelli, D. (2004). Different attentional resources modulate the gain mechanisms for color and luminance contrast. Vision Research, 44, 1389-1401.

MurRaY, S. O., \& He, S. (2006). Contrast invariance in the human lateral occipital complex depends on attention. Current Biology, 16, 606-611.

NACHMIAS, J. (1967). Effect of exposure duration on visual contrast sensitivity with square wave gratings. Journal of the Optical Soceity of America, 57, 421-427.

NaKayama, K., \& Mackeben, M. (1989). Sustained and transient components of focal visual attention. Vision Research, 29, 1631-1647.

Ogmen, H., Breitmeyer, B. G., \& Melvin, R. (2003). The what and where in visual masking. Vision Research, 43, 1337-1350.

PeLLI, D. G. (1997). The VideoToolbox software for visual psychophysics: Transforming numbers into movies. Spatial Vision, 10, 437-442.

Pelli, D. G., \& Zhang, L. (1991). Accurate control of contrast on microcomputer displays. Vision Research, 31, 1337-1350.

Pestilli, F., \& Carrasco, M. (2005). Attention enhances contrast sensitivity at cued and impairs it at uncued locations. Vision Research, 45, 1867-1875.

Pestilli, F., Viera, G., \& Carrasco, M. (2007). How do attention and adaptation affect contrast sensitivity? Journal of Vision, 7(7, Art. 9), $1-12$.

Prinzmetal, W., Long, V., \& Leonhardt, J. (2008). Involuntary attention and brightness contrast. Perception \& Psychophysics, 70 , 1139-1150.
Prinzmetal, W., Nwachuku, I., Bodanski, L., Blumenfield, L., \& Shimizu, N. (1997). The phenomenology of attention: Part II. Contrast and brightness. Consciousness \& Cognition, 6, 372-412.

Remington, R. W., Johnston, J. C., \& Yantis, S. (1992). Involuntary attentional capture by abrupt onsets. Perception \& Psychophysics, 51, 279-290.

Reynolds, J. H., \& Chelazzi, L. (2004). Attentional modulation of visual processing. Annual Review of Neuroscience, 27, 611-647.

Reynolds, J. H., Pasternak, T., \& Desimone, R. (2000). Attention increases sensitivity of V4 neurons. Neuron, 26, 703-714.

SCHNEIDER, K. A. (2006). Does attention alter appearance? Perception \& Psychophysics, 68, 800-814.

Schneider, K. A., \& Komlos, M. (2008, May). Attention biases decisions but does not alter appearance. Symposium conducted at the meeting of the Vision Sciences Society, Naples, FL.

Sмiтh, P. (2000). Attention and luminance detection: Effects of cues, masks, and pedestals. Journal of Experimental Psychology: Human Perception \& Performance, 26, 1401-1420.

Spivey, M. J., \& SpIRN, M. J. (2000). Selective visual attention modulates the direct tilt aftereffect. Perception \& Psychophysics, 62, $1525-1533$

Talgar, C. P., \& CARrasco, M. (2002). Vertical meridian asymmetry in spatial resolution: Visual and attentional factors. Psychonomic Bulletin \& Review, 9, 714-722.

Talgar, C. P., Pelli, D. G., \& Carrasco, M. (2004). Covert attention enhances letter identification without affecting channel tuning. Journal of Vision, 4, 22-31.

Treue, S. (2004). Perceptual enhancement of contrast by attention. Trends in Cognitive Sciences, 8, 435-437.

Tsal, Y., Shalev, L., Zakay, D., \& Lubow, R. E. (1994). Attention reduces perceived brightness contrast. Quarterly Journal of Experimental Psychology, 47A, 865-893.

Turatto, M., Vescovi, M., \& Valsecchi, M. (2007). Attention makes moving objects be perceived to move faster. Vision Research, 47, 166-178.

Williford, T., \& MAUnSELl, J. H. (2006). Effects of spatial attention on contrast response functions in macaque area V4. Journal of Neurophysiology, 96, 40-54.

WUNDT, W. (1902). Outlines of psychology (C. H. Judd, Trans.). Leipzig: W. Engelmann.

YESHURUN, Y. (2004). Isoluminant stimuli and red background attenuate the effects of transient spatial attention on temporal resolution. Vision Research, 44, 1375-1387.

Yeshurun, Y., \& CARRASco, M. (1998). Attention improves or impairs visual performance by enhancing spatial resolution. Nature, 396, 72-75.

Yeshurun, Y., \& Carrasco, M. (2000). The locus of attentional effects in texture segmentation. Nature Neuroscience, 3, 622-627.

Yeshurun, Y., \& CARRasco, M. (2008). The effects of transient attention on spatial resolution and the size of the attentional cue. Perception \& Psychophysics, 70, 104-113.

Yeshurun, Y., \& Levy, L. (2003). Transient spatial attention degrades temporal resolution. Psychological Science, 14, 225-231.

Yeshurun, Y., Montagna, B., \& Carrasco, M. (2008). On the flexibility of sustained attention and its effects on a texture segmentation task. Vision Research, 48, 80-95.

\section{NOTES}

1. The use of screen capture approximations and lack of monitor characterization and control of stimulus rendering are inadequate for experiments dealing with perceived contrast.

2 . The closer eccentricity and interstimulus distance raises the possibility that observers can more easily attend to both stimuli simultaneously, thus diminishing the possibility of selective attention to one stimulus over the other.

(Manuscript received April 11, 2008; revision accepted for publication June 13, 2008.) 